\title{
LEVENSBESCHRIJVING VAN JAN VAN DER TUUK; EEN STUK SURINAAMSCHE GESCHIEDENIS
}

DOOR

FRED. OUDSCHANS DENTZ

Op Donderdag den 18den Januari 1809 voer een Engelsch zeilschip in den vroegen morgen de Surinamerivier op en wierp ter hoogte van de stad Paramaribo het anker uit. Onder de reizigers bevonden zich de 59-jarige Jan van der Tuuk met echtgenoote en tien kinderen, van welke het jongste slechts twee jaar telde.

Het gezelschap had een gevaarlijke reis achter den rug.

Uit Amsterdam komende, was de familie den 15den September 1808 over Den Haag naar den mond van de Maas gereisd, waar men tegen middernacht aankwam. In het holst van den nacht vertrokken de reizigers in een open roeiboot de Noordzee op, hopende een schip te zullen ontmoeten, dat hen naar Engeland wilde overbrengen. Er bestond groot gevaar, dat men onderweg aangehouden zou worden, waardoor de reis kon worden verijdeld. Gelukkig ontdekte men een Nederlandsche visschersboot, waarop men kon overstappen. Op den 15den ontmoette men een Engelsche visschersboot, , Laby”. De kapitein gaf toestemming daarop over te gaan, en zoo zeilde men verder, totdat men den 16den Gravesend tegen 6 uur in den avond bereikte. Het gezelschap logeerde in de herberg ,White Hart”.

Den volgenden dag reisde men door naar Londen, waar men drie dagen later behouden aankwam en zijn intrek nam in het logement „Sablonière” op Leicester Square.

$\mathrm{Na}$ van de vermoeienissen van deze avontuurlijke reis te zijn uitgerust, koos men zee op een Engelsch zeilschip, dat koers zette naar Suriname, toen een Engelsche kolonie, een onbekende toekomst tegemoet.

Wie was Jan van der Tuuk ${ }^{1}$ ), die op meer dan middelbaren

1) Een afstammeling van Van der Tuuk, J. W. Enschedé, achterneef van Wernardine Jacqueline van der Tuuk, heeft in het 9de Jaarboek (MCMXI) van Amstelodanum een artikel geschreven: ,,Een uitwijking 
leeftijd met zijn groot gezin zulk een avontuurlijke reis ondernam om zich in een hem onbekend land te vestigen, waar hij niet alleen naam zou maken, maar zelfs een belangrijke plaats in gouvernementsdienst heeft ingenomen?

Hij was een Amsterdammer, den 12den Januari 1752 geboren en in 1774 met Anna Carolina de Wit gehuwd. Van beroep was hij koopman in lakens en zijden stoffen en hij dreef ook handel in wollen en katoenen manufacturen onder den naam Johan van der Tuuk en Comp. Hierdoor kwam hij tot zoodanigen welstand, dat hij in staat was de hofstede „Vreeland” in het Gooi te koopen.

Het huwelijk was niet gelukkig en werd door echtscheiding ontbonden. Van der Tuuk huwde op 10 November 1793 op ,,Vreeland" met Maria Helena Geertruyda van Liesveld, weduwe van mr. W. S. Q. Meurs, die in 1785 in Suriname tot Raad-fiscaal en president van het Hof van Justitie was benoemd en aldaar in 1787 was overleden. De weduwe was naar Nederland teruggekeerd. Bij dat huwelijk erkende Van der Tuuk het onechte tweejarige meisje Sophia Cornelia Maria, dat 14 October 1791 op ,Vreeland" geboren was en dienzelfden dag werd gedoopt.

Ofschoon Van der Tuuk de hofstede in 1788 verkocht aan een zekeren Pieter Glasmaker, bleef hij er wonen. Uit zijn huwelijk werden - het daarbij erkende kind inbegrepen - tien kinderen geboren, zes zoons en vier meisjes, die wij op hun reis naar Suriname hebben ontmoet.

Hadden de Europeesche oorlogen al slechten invloed op zijn handelszaak gehad, het continentaalstelsel deed deze nog meer verloopen, aangezien hij veel zaken op Engeland placht te drijven. Zijn sympathieën waren aan Engelsche zijde; hij was patriot en geen Oranjeklant.

Suriname was in 1804 een Engelsche kolonie geworden en het lag voor de hand dat, toen hij een ander vaderland trachtte te vinden, waar het hem beter zou gaan dan in Nederland, zijn oog op Suriname viel, waar zijn echtgenoote had gewoond en door haar eerste huwelijk bekend was.

\footnotetext{
van een Amsterdamsch koopman naar Paramaribo in 1808", waarvoor wij destijds een deel der gegevens verschaften uit het oud-archief der kolonie Suriname, sedert in het Rijksarchief alhier opgenomen. Aangevuld met vele andere bijzonderheden uit het Surinaamsche archief hebben wij die gegevens in dit artikel verwerkt.
} 
Toen Van der Tuuk dan in Suriname aankwam, was zijn eerste werk naar een betrekking uit te zien. De commandant der Troepen sir John Wardlaw was waarnemend gouverneur en werd 3 Mei 1809 door graaf Charles Bentinck opgevolgd.

Dank zij zijn Engelsche sympathieën en de relaties van zijn echtgenoote gelukte het hem, 17 dagen na zijn aankomst, n.l. 4 Februari tot 3de commies bij het comptoir der Hoofdgelden te worden aangesteld in de plaats van E. J. Wesenhagen, die tot 2 de assistent bij den Raad-Boekhouder-Generaal werd bevorderd.

Dit was de eerste stap op de ambtelijke ladder.

$\mathrm{Na}$ ruim een jaar, 6 Mei 1810, werd hij boekhouder-kassier van kerkegerechtigheid en secretaris van 's lands gasthuis. Hij legde als zoodanig op 26 Mei d.a.v. den eed in handen van den gouverneur ten overstaan van de Raden van Politie en Crimineele Justitie af. Binnen het jaar werd hij bevorderd tot ontvanger van het kantoor der landtaxen en op 19 Januari 1811 legde hij den eed in zijn nieuwe betrekking af.

Den 14den Januari 1814 benoemde de gouverneur hem tot Raad en Boekhouder-Generaal. Deze benoeming had hij te danken aan het uittreden van den heer A. Melville, die ontslagen was om de redenen, welke wij zullen laten volgen. Met deze promotie, waardoor zijn inkomen tot bijna $f 11.000$ per jaar steeg, had hij de hoogste trap op de ambtelijke ladder bereikt. Tegenover de Raden P. Heydoorn en W. H. Eyma legde Van der Tuuk den eed in zijn hooge functie af. Van zijn benoeming wordt in de Gepriviligeerde Surinaamsche Courant van 1 Februari no. 10 kennis gegeven. Bovendien werd hij in December van dat jaar tot secretaris van 't Edele College van heeren Commissarissen tot de zaken van de Nieuwe Wees-, Curateele en Onbeheerde Boedelkamer benoemd.

Wat was de reden van het ontslag van den Raad BoekhouderGeneraal Melville geweest?

Het Britsche gouvernement had op 12 Maart 1813 John Bent benoemd om in 's lands geldmiddelen orde te brengen. Hij kwam 15 Mei van dat jaar in Suriname aan als ,Ontvanger en bestierder, mede administrateur om aan de zijde van de Kroon generaallijk de administratie te controleren, van en over al de plantagiën of andere gronden doorgaans dezer colonie" zooals de proclamatie van gouverneur Pinson Bonham van 15 Mei 1813 luidde. Deze hooge functionaris kreeg een inkomen van $£ 30.000$ ! De gouverneur, door het Britsche gouvernement gesteund, verwachtte, 
dat Bent krachtige leiding zou geven aan het beheer der koloniale geldmiddelen, en toezicht op den handel, den verkoop van producten en de administratie van plantages zou houden. Van de heeren Raden van Politie en Crimineele Justitie, die meerendeels administrateurs van plantages waren, had de gouverneur weinig medewerking. Hun eigenbelang stond op den voorgrond. Bents benoeming wekte onder hen veel beroering en men achtte zich er door in zijn bevoegdheden geknot. Er heerschten allerlei misstanden in Suriname, vooral in het beheer der plantages. Erfenissen van in Nederland wonende eigenaren werden door de heeren in Suriname beheerd, alsof deze hun eigendommen waren. Daarin wenschte Bent ook veranderingen te brengen.

De moeilijkheden bereikten haar toppunt, toen Bent de balansen en gelden, toebehoorend aan boedels van den overleden F. Gomarus, groot $f 170.784$, en van P. Bloeddoorn, groot $f 27.000$, welke onder het beheer van de Weeskamer berustten, onder zijn beheer wenschte te zien gebracht, welk voorstel de gouverneur steunde. Vier maanden lang lieten de leden der Weeskamer den brief van den gouverneur onbeantwoord, en toen het antwoord op 3 Januari $1814 \mathrm{kwam}$, behelsde het een weigering. Bonham, die korte metten maakte, wenschte te worden gehoorzaamd en ontsloeg de onderteekenaars van den brief, n.l. den Raad-Fiscaal, E. G. Veldwijk, de 2de Fiscaal J. Lolkens, den Raad-BoekhouderGeneraal A. Melville en de Raden mr. M. S. Schüster, D. Rocheteau en H. L. Perret Gentil 1). Veldwijk was den gouverneur echter vóór en bood zelf zijn ontslag aan. Hierop benoemde de gouverneur Schüster tot Raad-Fiscaal. Aan den minister van Koloniën schreef Bonham op 19 Januari Van der Tuuk ${ }^{2}$ ) te hebben benoemd tot Raad Boekhouder-Generaal, ,,a gentlemen of considerable abitilities who has been long Collector of certain duties for the Sovereigns' Chest which he did greatly increase under Mr. Melville and I earnestly request the Confirmation of your Lordship" 3).

Zoo had dan Van der Tuuk, over wien zulke waardeerende woorden waren geuit, de hoogste ambtelijke positie in Suriname bereikt.

1) Wolbers noemt hem ten onrechte Pierre Gentil, blz. 584 .

2) Ook deze naam is onjuist bij Wolbers aangegeven als Van der Tank, blz. 584 .

3) Einaar, Bijdrage tot de kennis van het Engelsch tusschenbestuur van Suriname I804-I8I6, blz. 114. Hij spelt zijn naam ten onrechte Van der Tuuck. 
Zijn benoeming wordt in de notulen ${ }^{1}$ ) als volgt opgenomen:

,Maandag den 7e February 1814

Het hoff onder het presidium van Zijne Excellentie den Heer Gouverneur op de gewone ceremoniaale wijze vergaderd, wierd met den gebeede geopend:

Waarna de Heer Gouverneur was communiceerende dat hoogst derzelve niet dan met groot leedwezen verplicht was geweest sedert de laatste zitting van deezen hove, eenige veranderingen te moeten maken ten aanzien van de ministerieele betrekkingen. Dat zijn Hoog Edel Gestrenge den Heer Secretaris Mr. M. S. Schüster had aangesteld tot ad interim Eerste Raad Fiscaal met behoud van deszelfs feit als Eerste Secretaris en den Heere J. van der Tuuk tot Raad en BoekhouderGeneraal, terwijle den tweede Secretaris J. de Koff had gedispiceerd tot de waarneeminge van de Secretariale occupatien van deeze Hove.

En daar de nieuwe aangesteld Boekhouder-Generaal, de tot deszelfs aanzienlijke charge, staande eed had gearresteerd, was zijne Excellentie aan den hove voordragende om welgemelde Heer Raad en Boekhouder ter deese vergadering te introduceeren.

Het gunt gehoord en zijn hoog Edel Gestrenge voor deeze kennisgeving bedankt zijnde, is hetzelve voor communicatie aangenomen.

Wordende wyders den Secretaris verzogt en gecommitteerd om den Nieuw aangestelde boekhouder-Generaal van deszelfs wooning af te haalen en ter deese vergadering te introduceeren.

Het gunt geschied zijnde heeft welgemelde Heer Raad en boekhouder-Generaal na wederzeidsche aflegging der gewoone plichtplegingen zitting genomen.

Vervolgens heeft zijne Excellentie, den Heer Gouverneur, aan den hove gecommuniceerd, dat hoogst dezelve inplaatse van den Heer J. van der Tuuk had aangesteld den heer C. J. Wesenhagen tot secretaris van 's Lands gasthuys, alsmede tot kassier en boekhouder van de kerkegerechtigheid en welke in die betrekking den Eed had afgelegd.

Het gunt gehoord en zijne Excellentie voor deese kennisgeeving meede zijn bedankt wierd hetzelve voor communicatie aangenomen."

Van der Tuuk was blijkbaar een voorzichtig financier, die, zooveel als in zijn vermogen lag, trachtte de landsmiddelen goed op peil te houden, zooals blijkt uit onderstaande Memorie, welke hij op 20 December 1815 aan het Hof van Politie en Crimineele Justitie indiende, houdende een voorstel tot vernieuwing van de buitengewone belasting over het jaar 1815:

„Nademaal de ondergeteekende aan deese Edele achtbare Hove laatstleeden Vreydag heeft te kennen gegeven, dat in dat loopende jaar

1) Aanwezig waren met den gouverneur P. Bonham de ad interim Eerste Raad-Fiscaal mr. M. S. Schüster, de Raden P. Heydoorn, J. J. Ferrand, J. Bruyning, I. J. F. de Frederici jr., W. H. Eyma, E. K. Schelkes, A. A. Halfhide, C. L. Weissenbruch, M. S. Klein en de secretaris J. de Koff. 
de Extra ordinaire uitgave circa honderd een en twintig duysend guldens hebben beloopen en dat desniettegenstaande de staat van 's lands Financien zig op dit oogenblik nog in eene gunstige staat bevinden, zoo is den ondergeteekende dog Echter van oordeel, dat alle mogelijke voorzieninge dienen worden genoomen om 's Landscassen in die Zelve gunstige Positie te doen blijven en Souteneeren opdat in het volgende jaar, zoowel aan de ordinaire als Extra ordinaire betaalinge promptelijk zal kunnen worden voldaan, te meer het niet waarscheynlijk is, dat de Eerste minder zullen zijn, en Geheel onzeeker is, welke somma voor de laatste zal gevorderd worden, weshalve den ondergeteekende zich in de verplichting vindt (hoe gaarne ook geneegen het Publiek van Eenige van de Extra Ordinaire lasten te ontheffen) dezelve nog voor Een jaar te moeten continueeren.

Reedenen waarom den ondergeteekende zich by deese Edele achtbare Hove vervoegt Eerbiediglijk voorstellende, nog voor een tijd van Een jaar deese volgende Extra ordinaire Belastinge te hernuwen, en dat wel aanvang neemende met den Eerste January 1815.

$1^{\circ}$. het Extra Temporaire Hooftgeld ingevolge Publicatie dato 4 November 1805 den 20 of 26 daaraan gepubliceert en successievelyk met den 20 en 26 Decemb. 1813 hernieuwd,

$2^{\circ}$. De Extra Belasting op het zeegel bekend ingevolge de Publicatie dato 4 Novem. 1805 en successievelijk hernuwd tot Decemb. 1813,

$3^{\circ}$. de quotisatie van de Huur van de Huysen en Erven binne de stad Paramaribo en ressorten van Dien, als bepaald is volgens de Proclamatie Dato 10 Feb. 1812 en Hernuwd Decemb. 1813.

Al hetwelk den ondergeteekende aan het Wijs oordeel van deese Edele Achtbaare Hove overlaat, ten Einde naa bevinding van Zaaken, daarover te oordeele en beslissen."

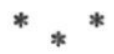

Wij gaan de strubbelingen, welke in het Engelsche tusschenbestuur zijn voorgevallen verder voorbij. Het stoken en lasteren tegen Bent eindigde ten slotte met zijn ontslag op 8 Juni 1814 en vertrek uit Suriname op den 18den Juli d.a.v.

In 1815 kreeg Nederland de kolonie terug en vertrok de eerste Gouverneur-Generaal Willem Benjamin van Panhuys daarheen, die het bestuur op 27 Februari 1816 overnam. In de Proclamatie van dien dag werd, behalve vele anderen, ook Van der Tuuk als Raad-Boekhouder-Generaal ontslagen, ,echter voor behoudens derzelver verantwoordelijkheid".

Voor het overnemen van zijn kantoor werden 27 Februari aangewezen de Raden F. Beudiker en G. N. Linck. Deze vervoegden zich ten huize van Van der Tuuk om inlichtingen en ophelderingen inzake zekere geldelijke transacties, welke deze 21 Mei schriftelijk vastlegde in den brief van den volgenden inhoud, welke het Hof op 27 Mei d.a.v. voor notificatie aannam. 
HoogEdeleGestrenge Edelachtbare Heeren,

Tot voldoening aan de verlangens van deesen Edele achtbaare Raad, op de vraagen van den Secretaris J. de Koff. per Missive dato 18 deeser uyt naam van deesen Edele Achtbaare Hove gdaan,

om in Scriptie den Hove te verwittigen of door Zijn Excellentie den voormalige Gouverneur P. Bonham, aan de vervulling van $\mathrm{Zijn}$ Hoog Ed. Gestrenge Belofte, en aannaame ter dispositie van de bij notulen genoemde somma's als al het verdere bij notulen vermeld, en gementioneerd, voldaan zy, waarop den ondergeteekende de Eere heeft het volgende te berigten:

Dat wanneer het oogenblik Zijn Excellentie den voormalige Gouverneur P. Bonham, aan deese Edele Achtbare Hove te kennen gaf, zijn bereydwilligheid om het Publiek ten kosten van Zijn Majesteit den Koning van Engeland ten dienst te staan,

en ter geruststelling en voldoening, van de nog onbetaalde en ongevideerde commando Rekeningen betaalbaar bij de Cassa teegen de wegloopers, volgens notulen van 23 February 1.l. en missive daarbij overgelegt op vijf en dertig à veertig duysend guldens zijnde begroot, zoude vaststellen en deponeeren eene somme van vier en veertig duysend guldens Gelden aan het comptoir der Cassa teegens de wegloopers, ter leen voorgeschoten.

Tot informatie van dit Eerste Poinct dient, dat deese somma van vier en veertig duysend guldens oorspronkelijk zijn, voor zooverre den ondergeteekende zig kan herinneren, uyt Een subsidie, die de welwillendheyd van zijn Excellentie den Gouverneur indertijd heeft kunnen goed vinden uyt Een der Koning's cassen (namentlyk die van de Hooftgelden) aan Een der Coloniale cassen (namentlyk de cassa teegens de wegloopers) voor te schieten, ten einde de menigvuldige betaalinge dien het laast van het voorleedene jaar, van 't corps coloniale Jagers van het comptoir der cassa teegens de wegloopers gevorderd wierden, tegemoet te komen.

Deese voormelde subsidie van vier en veertig duysend guldens behoorde reeds in de maand Maart uyterlijk April, geheel of ten deele zyn afgedaan geweest; wat reeden den ontvanger van 't comptoir der cassa teegens de wegloopers dit heeft versuymt, moet den ondergeteekende volkoomen ignoreeren. De WelEdele Achtbare Heeren Raaden, die ter dien tijd in den Raad Present zijn geweest, en daar nog aanweezig zijn, zullen in concurentie met den ondergeteekende niet kunnen ontkennen, maar wel deegelijk vaststellen, dat deese vier en veertig duysend guldens door een der Konings cassen aan den Landen voorgeschoten, ook wederom van den Landen, ån Koning's cassa behooren terug te keeren, in dier voege als gewoonlijk ten opzigte alle voorgaande subsidien bij de Lands Publique Comptoire heeft plaats gehad en gebruykelijk is.

Om welke reedenen dan ook den ondergeteekende moet veronderstellen, dat deese vier en veertig duysend guldens zoo dikwijls hier vooren gementioneerd, door $\mathrm{Zijn}$ Excellentie de thoenmalige Gouverneur P. Bonham, representeerdende Zijne Majesteit, by die gelegenheyd, als Eene deugdelijke onderpand zyn aangemerkt geworden en tot de voornoemde bedoeling daargesteld. 
Schoon den ondergeteekende zig geensins wil Inlaaten in de materie van de zaak, daar hem alleen genoeg is oplossing te hebben gegeven, waar en hoedanig deese $f 44.000$ gedeponeerd zijn geworden.

Ten opzigte van het tweede poinct, waarby Zijn Excellentie andermaal goedvind zijn welwillendheyd aan den dagh te leggen, en zegt:

,,booven-dien nog voorneemens was, te stellen en te deponeeren plus Minus Eene somma van sestig duysend guldens, ter voldoening en vereffening voor zooverre die zoude moogen strekken, voor de zoodaanige commando Rekeningen waarvan bij het Compt. der vendu gerecht gewoonlijk de betaalingen worden gedaan, en waartoe $\mathrm{Zijn}$ HoogEdelgestrenge Een Commissaris zoude benoemen, en alhier verblijven voor den tijd van de drie Eerstkomende maanden".

Ten opzigte van het laatste poinct, vind den ondergeteekende zig bezwaard meer te antwoorden als alleen:

Dat aangezien de waare achting, en 't behoorlyk respect, die den ondergeteekende bij alle geleegendheedens $\mathrm{Zijn}$ Excellentie den voormalige Gouverneur P. Bonham heeft toegedraagen, om den Plicht in Zijne relatie als Raad en Boekhouder-Generaal maar al te wel kennende, zig niet veroorlooft heeft gevonden, om van $\mathrm{Zijn}$ Excellentie den Thoenmaalige Gouverneur de Detailles van Hoogst desselfs Voorneemen, Pertinent af te vraagen, of te wel in Hoogst desselfs Particuliere geheymen in te dringen, Uyt dien hoofde is, en blijft deese vraage, weegens de dispositie van Zijn Excellentie, ten opzigte dit laatste poinct voor den ondergeteekende onoplosbaar.

Vertrouwende hiermeede voldaan te hebben aan de Instructie van deesen Edel Achtbaare Hoove, ten opzichte de gerequireerde Informaties p. Missive van den Secretaris J. de Koff, zoo verblijve met alle verschuldigde Hoogagting HoogEd. Gestrenge WelEdelachtbaare Heeren,

Uw HoogEd. Gestr. \& WelEdele Achtbare Ootmoedige Dienaar (w.g.) J. VAN DER TUUK.

Aan den Edele Achtbaare Hove van Politie en Criminele Justitie deser Colonie \& \& \&.

In het zelfde jaar eindigde Van der Tuuks ambtelijke loopbaan. Wij vervolgen ons verhaal door een en ander uit zijn particuliere leven mede te deelen.

Toen hij uit 's lands dienst ontslagen werd, was Van der Tuuk 64 jaar oud en een welgesteld man. In 1818 besloten de heer en mevrouw Van der Tuuk ten behoeve hunner kinderen een plantage in Suriname te koopen. Hun oog viel op „Vreedenburg”" aan de Parakreek, een suikerplantage van bijna 3500 akkers, waarvan hij zelf reeds administrateur was met $\mathrm{C}$. L. Weissenbruch. Hij kocht de plantage voor de som van $f 160.000$ van den heer W. F. Schuyt te Amsterdam. Het transport had 11 Februari plaats. In verband met een op dit „effect” te vestigen hypotheek 
en tengevolge van het verblijf in het buitenland van zijn dochter, die met den officier van gezondheid Sharp gehuwd was, zonden zij aan den gouverneur een request, waarin zij verzochten goed te keuren, dat de heer A. Cameron, een vriend van Sharp, als diens gemachtigde of vertegenwoordiger zou mogen optreden. Zij schreven:

„Aan Zijne Excellentie Mr. Cornelis Reynhard Vaillant, GouverneurGeneraal ad interim der colonie Surinamen, mitsgaders opperbevelhebber van Zijn Majesteit's Land- en Zeemagt binnen de voorz. colonie.

Geven eerbiedig te kennen J. van der Tuuk en Maria Helena Geertruyda van der Tuuk geboore van Liesvelt, Echtelieden,

Dat de supplianten, ten behoeve van hunne gezamentlijke kinderen hebben gekogt van den heer W. F. Schuyt, te Amsterdam, de plantage Vreedenburg, geleegen binnen deeze colonie, onder deeze zeer voordeelige conditie, van daarop eene Kusting te vestigen, voor de koopwaarde ter somma van $f 160.000$ Surinaamsch geld, terwijl dit capitaal by jaarlijksche termijnen uit de voortbrengselen van die plantage moet worden gekweeten.

Dat hoezeer de supplianten als ouders, in ex natuur voogden wel voor hunne minderjarige kinderen by het ooverlijden transport kunnen compareeren, en derzelvens belangen representeeren, bij het te vestigene kusting, op dat Effect, zij echter niet wel kunnen paroiseeren voor hunne meerderjarige dochter Sophia Cornelia Maria van der Tuuk gehuwd aan den heer Jas Sharp, welke tegenwoordig uitlandig is, en geene gemachtigde alhier heeft, zoodat hiertoe een persoon behoord te worde gecommiteerd, die haar belangen representeerd.

Zoo neemen de supplianten de vreyheid, Uwe Excellentie voor te dragen, den heer Adam Cameron, die uithoofde van byzondere vriendschapsbetrekking, met der supp.ten aanbehuwde zoon, zich met deze commissie wel wil chargeeren, en ten blijke deeze meede heeft onderteekend, met verzoek, denzelven te comiteeren, tot curator ad hunc actum, ten einde de belangen van der supplianten voormelde dochter te representeeren, zoo bij het ontvangen van het transport, der door de supplianten, ten behoeve, van hunne gezamentlijke kinderen, gekogte plantage Vreedenburg, als het verlijden van de kusting welke op voormelde Effect van het montant van de koopschat moet worden gevestigd.

Paramaribo, den Maart 1818

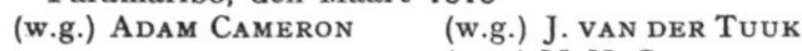

(w.g.) M. N. G. VAN DER TUUK

geboore VAN Liesvelt.

Het echtpaar van der Tuuk had, zooals wij tevoren hebben medegedeeld, 4 dochters en 6 zoons.

De oudste dochter Sophia Cornelia Maria huwde in 1811 op 
haar 19de jaar met den Schotschen geneesheer, in dienst bij het 16de regiment van de Britsche troepen, James Sharp, oud 30 jaar. Zij overleed in den hoogen ouderdom van 95 jaar in 1887 in Mira buiten Venetië, waar zij met haar zuster Wernardine Jacqueline samenwoonde. Sharp werd na de overneming van de kolonie door Van Panhuys met andere militairen naar Demerary overgeplaatst, waar hij, slechts 44 jaar oud, in 1825 overleed.

Onder de inwoners van Suriname had Sharp zich in zijn ambt als chirurgijn der troepen vele vrienden gemaakt. Bij zijn vertrek bleek het, hoe men hem waardeerde, door de aanbieding van een geschenk met huldeadres van den volgenden inhoud: 1)

\section{Mijnheer!}

Suriname den 15e Maart 1816

Ten bewijze onzer vriendschap en als een Teeken van die Agting met welke wij U karacter zoo lang in de samenleving beschouwt hebben, vergun Ons, Eer gy deeze Colonie Surina me verlaat, $U$ te verzoeken een stuk Zilver ter waarde van Honderd Gueneas van Ons te willen accepteeren; het zelve zal $U$ ter hant gesteld worden door Messrs Rundel en Bridle Juweliers Zijner Majesteyd, Ludgate Hill, London.

By dit teeken onzer Agting voegen Wij onze beste wenschen voor $U$ gezondheid en aangenaaame reys met U Familie naar Engeland. Wij zijn, Mijn Heer,

U getrou we vrienden \& D.W. dienaaren: J. Frederici, E. Conoly, A. W. De Mey, A. Bentinck, W. van der Tuuk, W. Leckie, J. Black, A. White, G. Cruden, Adam Cameron.

Den WelEdele Heer JAMES SHARP.

Chirrurgyn der Land Troepen.

De andere dochter Georgine Louise Charlotte Antoinetta huwde 29 September 1822 met den 30-jarigen mr. Charles François Mirandolle, lid van den Hove van Civiele Justitie en Auditeur Militair in Suriname. Hij was in Breda geboren als zoon van Henry Mirandolle van Gheert, in leven president van het Departementaal geneeskundig onderzoek en medicinae doctor te 's-Gravenhage en Maria Anna van den Kieboom.

De derde dochter, Wernardine Jacqueline, geboren 27 April 1806, werd ter voltooiïng harer opvoeding naar Europa gezonden en woonde te Brussel bij mr. Baumhauer, Advocaat-Generaal bij het Hooggerechtshof aldaar. Na het overlijden van haar zuster Georgine huwde zij met haar zwager Mirandolle, en na diens overlijden, dus voor de derde maal, met den luitenant der huzaren L. A. J. Vermasen. Toen ook deze stierf, ging zij met haar oudste

1) Surinaamsche Courant, Zaterdag 23 Maart 1816, no. 24. 
zuster, de weduwe Sharp, samenwonen. Zij zelve overleed in den hoogen ouderdom van 104 jaar op 19 Juni 1910 als de oudste inwoonster van Haarlem.

Van de vierde dochter Magdalena is ons niets naders bekend.

Een der zoons van Van der Tuuk, Sigefridus, kwam op tragische wijze op de plantage „Wayampibo" om het leven en werd daar in December 1816 begraven. Jan overleed op jeugdigen leeftijd op 16 April 1810. Van Nicolaas Laurens Renard weten wij, dat hij een begaafde jongen was, die als een der verdienstelijkste leerlingen van den Nederlandschen onderwijzer J. Vrolijk te Paramaribo op 1 September 1819 een eereprijs ontving.

Abraham legde, toen hij 17 jaar oud was, zijn belijdenis af op 11 April 1811 in de Gereformeerde kerk, in een dienst die ds. P. J. van Esch in het Luthersche kerkgebouw hield. Hij werd ontvanger van het kantoor der landtaxen in Januari 1814, dezelfde betrekking als zijn vader eenmaal had bekleed. Bovendien was hij 2de luitenant bij de 3de Compagnie van de Schutterij te Paramaribo. Toen hij voornemens was een reis naar Europa te ondernemen, gaf hij daarvan in de Surinaamsche Courant van 2 Juni 1920 kennis, zooals was voorgeschreven. Hiertegen verzetten zich volgens het Oppositieboek om ons onbekende redenen op 6 Juni verscheidene personen, t.w.: C. van Elmpt qq, mede voor G. H. C. Black, J. H. Rooswijk, M. W. van Middachten, John Sowerly, John Henry en zekere Wesenhagen. Of hij vertrokken is, hebben wij niet kunnen vinden. Hij overleed 4 Juni 1823 ten huize van zijn zwager Mirandolle.

Johannes Wilhelmus was een andere zoon. Hij gaf kennis in de Surinaamsche Courant van 25 April 1818 no. 24 tot herstel van gezondheid naar Europa te willen vertrekken. Tevoren had hij een verzoekschrift aan den gouverneur ingediend om handlichting te bekomen, luidende:

Aan Zijne Excellentie Mr. C. R. Vaillant, Gouverneur-Generaal ad interim der kolonie Suriname, mitsgaders opperbevelhebber van den Land- en Zeemagt in de zelve, \& \& \&.

bij non cessie 1) van den Edele Achtbaare Hove van Politie en Crimineele Justitie der voorsz. kolonie, \& \& \&.

Geeft met schuldige Eerbied te kennen, J. W. van der Tuuk,

dat den suppliant bereykt hebbende twee en twintig jaaren, volgens hierbij gevoegde doop attestatie en alzo den suppl. zig in staat gevoeld zyne zaaken en belangen zelfs waar te nemen en gaade te slaan,

Wenschte hij te hebben suppletie van jaaren.

mits welke hij bij non cessie 1) van 't Hoff van Politie Uw Excellentie

1) Aldus in het stuk gespeeld. 
adieerd met verzoek, daar den suppl. van voorneemen is, om tot herstel van zijn gezondheid binnen kort eene reis naar Europa te doen, aan hem voor zijn vertrek te willen accordeeren en verleenen Brieven van venia aetatis of te suppletie van jaaren, met authorisatie of Hoogstdeszelfs Heer Secretaris derzelve aan den suppliant tegens betaaling der kosten te Extraheeren.

Paramaribo, den 15 April 1918

't welk doende, \&

(w.g.) J. W. VAN DER TUUK

Wij ondergeteekenden, ouders van den requestrant, consenteeren in dit voorstaande verzoek.

Paramaribo, 15 April 1818 (w.g.) J. VAN DER TUUK

(w.g.) M. H. G. VAN DER TUUK, geboren VAN Liesvelt.

't Hof accordeert favorable brieven van overschrijving aan den Gouverneur C. R. Vaillant.

Paramaribo, 19 April 1818.

Ter ordinantie van den Hove P. J. Changuion.

In buitengewone zitting heeft het Hof het verzoek goedgekeurd en ofschoon ook tegen zijn vertrek in het Oppositieboek bezwaren werden ingediend door Jb. Sanches, Elisabeth Seyler, M. L. Nassy en S. E. Godefroy, is de reis toch doorgegaan. Immers wij zien in het register van aangekomen passagiers, dat hij met het schip ,Lodewijk Anthony”, schipper B. Staghouwer op 3 December 1819 uit Amsterdam in Suriname terugkwam, met een pas, welke den 15den Mei 1818 te Paramaribo was uitgereikt.

Van hem wordt vermeld, dat hij „Coloniaal Commissaris” was. Hij overleed 15 Mei 1821.

Een andere zoon was blijkbaar William, van wien wij alleen lezen, dat hij op den 18den Januari 1816 tot Inspecteur van het Cordon met den rang van Majoor was aangesteld, welke benoeming echter bij Notificatie van den 30sten d.a.v. werd ingetrokken.

Mevrouw Van der Tuuk kwam 20 November 1820 te overlijden, oud 54 jaar. Van der Tuuk droeg, behalve zijn echtgenoote, vijf zijner zoons ten grave, zoodat zijn laatste levensjaren niet van de gelukkigste waren.

Bovendien ging het de plantage slecht. De exploitatie liep op een fiasco uit en zij was een totale mislukking door oorzaken, welke wij hier niet verder zullen uiteenzetten.

De hoofdpersoon van ons verhaal, Jan van der Tuuk, overleed 30 April 1824 op 72-jarigen leeftijd in betrekkelijke armoede na een veelbewogen leven. Zijn nalatenschap werd door zijn 
schoonzoon Mirandolle niet aanvaard en verviel aan de Nieuwe Wees-, Curateele en Onbeheerde Boedelkamer. Een aankondiging in de Surinaamsche Courant van 7 Mei 1824 no. 37 daarover luidde:

Kurators der Nieuwe Wees, Kurateele en onbeheerde Boedels Kamer dezer Kolonie zullen op Woensdag den 12den dezer des nademiddags om vier uren ter sterfhuize van wylen den Heer Jan van der Tuuk, publiek verkoopen, deszelfs nalatenschap bestaande in meubilaire goederen. Manskleeren en hetgeen verders ten voorschijn zal worden gebracht.

Alsmede 10.000 cingels en 20 stuks copie planken van de Houtgronden La Ressource en Sonnette, aankomende den Boedel M. Schelkes. Paramaribo, den 7 Mei 1824 (w.g.). J. DE HEYDER Gekw. le gesw. Klerk".

De verkoop heeft inderdaad plaats gehad; ook van de kleeren van den heer en van Mevrouw Van der Tuuk, welke uit het sterfhuis in het magazijn van de Curateelekamer waren overgebracht en door den 2den gezworen klerk in ontvangst genomen.

Volgens het notulenboek van de Weeskamer verklaarde de heer Mirandolle deze goederen bij prisatie te willen overnemen, hetgeen op 24 Juni heeft plaats gehad, ingevolge de machtiging van het college van 17 Juni 1824, zoo voor zich, als voor de medeerfgenamen der echtelieden.

Ten slotte kunnen wij nog vermelden, dat in de Surinaamsche Courant van Dinsdag 6 Juli 1824 no. 54 wordt geadverteerd, dat „,aan de Nieuwe Wees-, Curateele en onbeheerde boedels Kamer zijn gedevolveerd de volgende boedels:

„13/96 Aandeelen in de Plantage Vreedenburg, gelegen aan de Parakreek, aankomende den Boedel J. W. van der Tuuk, 13/96 Aandeelen in den idem, aankomende den Boedel Abraham van der Tuuk.

1/16 Aandeelen in idem, aankomende den Boedel Jan van der Tuuk."

en in de Surinaamsche Courant van Woensdag 20 October 1824, no. 84:

,dat aan diezelfde Boedelkamer gedevolveerd (zijn) de navolgende Boedels als van Jan van der Tuuk den 1ste Mei 1824. 1/16 Aandeelen in de Plantagie Vreedenburg, gelegen aan de Parakreek aankomende de Boedel Jan van der Tuuk." 